\title{
A Comprehensive Analysis of Factors Influencing Quality of Requirements
}

\author{
V. Suma and B. R. Shubhamangala
}

\begin{abstract}
Successful deployment of software projects in any industry is dependent on quality of requirements. Quality of requirements is analyzed through quality influencing factors, quality associated criteria and quality related metrics. This paper brings in comprehensive analysis of the current strategies existing in software industries which aims to achieve high quality requirements. The research work undertaken here illustrates an investigation carried out on several projects developed in various software industries in order to comprehend the above stated objective. The investigation results indicate existence of variations between observed quality levels in requirements with the expected level of quality of requirements. Awareness on quality level of requirements certainly aims towards reduction in failure of projects and subsequently leads towards success of the company.
\end{abstract}

Index Terms-Software engineering, quality requirements, metrics, project success.

\section{INTRODUCTION}

Successful Information Technology (IT) projects are the key to drive the companies towards the creation of bench mark in fierce business competitive world. Current industrial environment make mandatory for all IT organizations to dev develop successful products. Thus, the success of the project is defined in terms of product which is developed in faster, cheaper with high quality, which gains customer satisfaction [1]. Success can be achieved to the fullest form therefore by unambiguous, consistent and complete requirements [2]. Hence, requirements play an essential role in growth and survival of organizations today.

Core requisite of requirements is that it forms the basis for starting the project. However, in real time scenario, requirements can creep across every activity, milestone and during every deliverable of the project. Looking from the rational edge, success of project is defined by requirements. Conventional view towards requirement engineering process is that it is a platform to start the project but subsequent stages of project are independent of requirements. Software development activities depend on elicited requirements across every phase of project from inception through post deployment.

Fig. 1 illustrates activities of the project which depends on elicited requirements

Manuscript received January 25, 2013; revised April 18, 2013.

V. Suma is with Research Industry Incubation Centre, Dayananda sagar Institutions, Bangalore-75 (e-mail: sumavdsce@gmail.com).

B. R. Shubhamangala is with Department of MCA, Dayananda sagar Institutions, Bangalore-75 (e-mail: brmshubha@gmail.com).

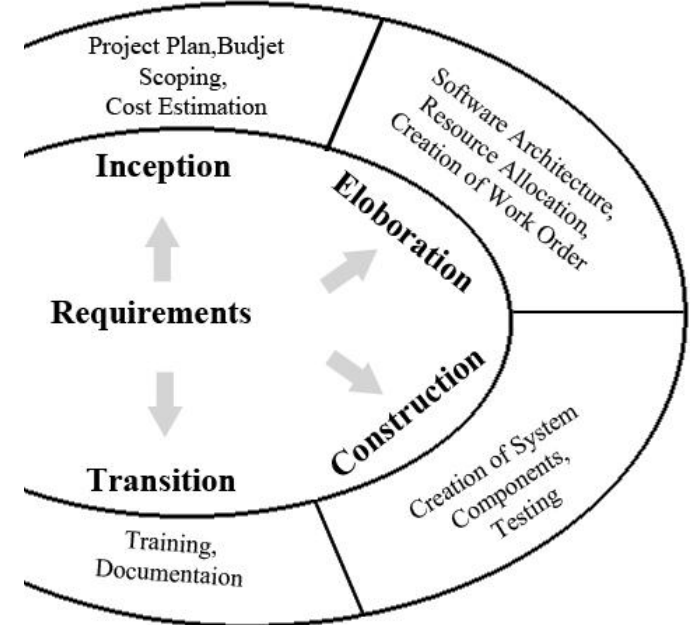

Fig. 1. Activities where comprehension of requirements are involved.

From the above Fig. 1, it is evident that inception, elaboration, construction and transition are the four phases of software development life cycle (SDLC) and requirements forms the base for all the activities of SDLC phases. Requirements must be potential enough in terms of complete, consistent and unambiguous in order to develop a customer satisfied software during SDLC process [3], [4]. To possess enough potential to drive the above tasks, requirements must meet the highest quality. Quality cannot be imposed into the end product and must be embedded throughout SDLC phases. Primarily, quality must be embarked at the base level-i.e. requirements formulation level. Requirements of poor quality affect the subsequent stages of product development [5], [6]. Effects of poor quality requirements are depicted in Table I.

TABLE I: EFFECTS OF POOR QUALITY REQUIREMENTS

\begin{tabular}{|l|l|}
\hline $\begin{array}{l}\text { Impacts of poor } \\
\text { quality } \\
\text { requirements }\end{array}$ & Underplaying Reasons \\
\hline $\begin{array}{l}\text { Increase in cost and } \\
\text { schedule }\end{array}$ & $\begin{array}{l}\text { Effort is spent on figuring real business needs of } \\
\text { requirements stated principally in design and } \\
\text { implementation stages }\end{array}$ \\
\hline $\begin{array}{l}\text { Decrease in product } \\
\text { quality }\end{array}$ & Increased defects \\
\hline $\begin{array}{l}\text { Increase } \\
\text { maintenance effort }\end{array}$ & $\begin{array}{l}\text { Lack of traceability increases the effort to identify } \\
\text { where changes are required, }\end{array}$ \\
\hline $\begin{array}{l}\text { Customer } \\
\text { dissatisfaction }\end{array}$ & $\begin{array}{l}\text { Ambiguity causes differences in customer } \\
\text { expectations and delivered product }\end{array}$ \\
\hline
\end{tabular}

From the above table it is evident that requirements of high quality are essential to deliver successful projects. Hence, this research aims to explore all the factors influencing the quality of requirements in software organizations.

Organization of the paper is as follows. Section I comprises of the introduction given above. Section II provides a survey on the related work. Section III briefs the 
design of research through research methodology. Section IV provides explanation on the research undertaken and Section $\mathrm{V}$ concludes the paper.

\section{LITERATURE SURVEY}

Quality of the software developed plays an important role in profitability of industry. Further, quality of the requirements provides the basis for desired level of software quality to be deployed. The crucial quality attributes such as scalability, reliability, availability, integratability, extensibility, adaptability, modularity, evolvability, recoverability are heavily reflecting on quality of requirements. Authors in [7] states that it is identified that project failure is caused due to absence of a set of essential requirement practices. However, they further express that those requirement practices are never implemented in projects. Author in [8] feels that customer perceived quality metrics in the final product is very important for the survival of the organization. Author in [9] express the need of software metrics in software development project. Authors of [10] also recommend the implementation of software quality metrics towards realization of successful projects. Authors in [11] suggest implementation of adaptability metric in requirements phase which influences the quality of software architecture. Authors in [12] express that requirement engineering has a great impact on success of project. Authors in [13] express requirement volatility rate is very high if requirements elicited are not accurate.

Thus, high quality requirements during software development are very critical for the success of the project. This paper therefore focuses upon comprehending the strategies practiced in the industry, in order to achieve quality requirements during software development process.

\section{RESEARCH Methodology}

This investigation comprises of an analysis of several projects developed in various software industries in order to bring awareness of quality of requirement engineering process. In order to achieve the above said objective, subject matter experts, program managers, quality managers, developers, test managers, business analysts, operational managers of various software industries were interacted. They were given questionnaires to find the factors affecting the quality of requirements. Responses to questionnaire were analyzed to view the factors needed to improve the quality of requirements from the perspective of software industries.

\section{RESEARCH WORK}

This investigation aims to bring in awareness on level of quality of requirements. Quality of requirements can be viewed from three perspectives namely

1) Quality criteria

2) Quality factor

3) Quality metrics

The above dimension of quality can be represented in a diagrammatic way as given in Fig. 2.

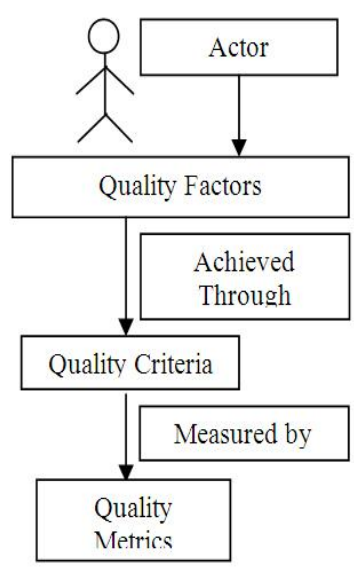

Fig. 2. Dimensions of quality.

Customer expectations of quality are measured in terms of quality factors which play a pivotal role in determining the degree of customer satisfaction. Quality criteria are set of attributes which indicates if the quality factors are satisfied or not in the product. As an instance, modularity is a quality criterion which could be used to measure maintainability. There exists several quality metrics which acts as the indicators to measure software product quality [14]. The metrics further gives the visibility of the level of quality achieved in the product.

TABLE II: QUALITY FACTOR AND QUALITY CRITERIA

\begin{tabular}{|l|l|}
\hline Quality Factor & Quality Criteria \\
\hline Functionality & $\begin{array}{l}\text { Suitability, Accuracy, Interoperability, } \\
\text { Security, }\end{array}$ \\
\hline Reliability & $\begin{array}{l}\text { Maturity, fault tolerance, Recoverability, } \\
\text { Reliability Compliance, Availability }\end{array}$ \\
\hline Usability & $\begin{array}{l}\text { Understandability, Learnability, Operability, } \\
\text { attractiveness, usability compliance }\end{array}$ \\
\hline Efficiency & Time behavior, Resource utilization \\
\hline Maintainability & $\begin{array}{l}\text { Analysability, Changeability, Stability, } \\
\text { Modularity, testability, maintainability } \\
\text { compliance, reusability }\end{array}$ \\
\hline Portability & Adaptability, Installability, replaceability \\
\hline Security & $\begin{array}{l}\text { Confidentiality, integrity, non repudiation, } \\
\text { Accountability }\end{array}$ \\
\hline
\end{tabular}

The above mentioned theory can be alternatively supported in a mathematical representation as given below.

$$
q_{r}=f\left(q_{f}\right)
$$

where $q_{r}=$ Quality of requirements which is a function of quality factors.

Quality factor can be further expressed as a set of quality criteria

$$
q_{f}=\left\{q_{c 1}, q_{c 2}, q_{c 3} \ldots q_{c n}\right\}
$$

where

$q_{f}$ is Quality Factor,

$q_{c 1}, q_{c 2} \ldots q_{c n}=$ Quality Criteria

A quality criterion is a function of quality metric and can be expressed as

$$
q_{c}=f\left(q_{m 1}, q_{m 2}, q_{m 3} \ldots q_{m k}\right)
$$


Table II provides list of major quality factors and corresponding quality criteria.

Requirements Quality measurement:

Quality of requirements is dependent on process, product and people. Quality can be enhanced and controlled only if the current status of requirements quality is measured. Appropriate tool to measure the quality of requirements is goal question metric (GQM) method. GQM includes four phases namely planning, definition, data collection and interpretation. Implementation of GQM is represented below in Fig. 3.

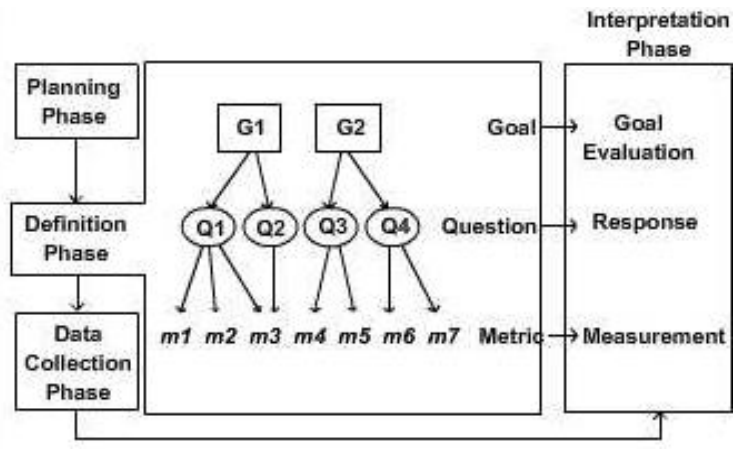

Fig. 3. GQM methodology.

\section{A. Planning Phase}

In this phase selection of projects, planning for the execution of GQM is carried out. Selection of respondents from industry is planned where the respondents were selected in three levels. The first level had respondents from executive level containing, Chief technology officer (CTO), chief compliance officer (CCO) and Subject matter expert (SME). Second level respondents were project manager, program manager, quality analyst, quality manager. Third level respondents include team lead, developers, module leaders, auditors and reviewers.

\section{B. Definition Phase}

In this phase goals, questions and metrics were formulated and documented. From the discussion with project development team, the major challenges faced by the industry towards the development of quality requirements were noted. These challenges turned out to be questions. Further, these challenges spanned from the basic need of requirements till critical quality needs. They include obtaining reply to queries such as: - Are the elicited requirements capable of providing optimum coupling with modularity? And so on. Questions were directed to analyze the challenges faced in quality aspects of requirements engineering and the current industrial strategies followed to overcome those challenges.

The goal is sub divided into set of goals. Each goal is translated into questions. Metrics were designed to provide the answers to these questions. By obtaining the responses to questions and henceforth the operational analysis of responses leads to identify whether or not the goals are attained.

\section{Data Collection Phase}

In this phase the questionnaire to analyze the challenges was given to respondents. Each respondent was asked to respond to the question by stating the percentage of achievement in each question asked. Respondents were also asked to justify their answer and to give grading wherever applicable. Averages of all the responses were taken and inferences are thus drawn. Table III provides the information of questions and responses.

TABLE III: QUESTIONNAIRE TO ANALYZE THE CHALLENGES

\begin{tabular}{|c|c|}
\hline Q.1 & Is the $\mathrm{Rq}$ correct as per customer expectation? \\
\hline Response & $\begin{array}{l}\text { Up to } 70 \% \text { is achieved. From customer feedback and } \\
\text { post delivery defect density it is evident. }\end{array}$ \\
\hline Q.2 & $\begin{array}{l}\text { Is the requirement consistent with design and } \\
\text { implementation }\end{array}$ \\
\hline Response & $\begin{array}{l}\text { Bugs in Design and implementation hopping back to Rq. } \\
\text { Consistency is achieved to } 80 \% \text { with } 10 \% \text { of requirement } \\
\text { volatility. As volatility has increased consistency } \\
\text { decreases. Consistency increases on an average by } \\
20 \% \text { for one percent increase in Volatility }\end{array}$ \\
\hline Q3 & Does $\mathrm{Rq}$ provide accurate results? \\
\hline Response & $\begin{array}{l}\text { Not all the times. Accuracy is achieved is dependent on } \\
\text { project parameters. On an average } 89-95 \% \text { accuracy is } \\
\text { achieved .( By ACM-Annual contract maintenance) }\end{array}$ \\
\hline Q4 & $\begin{array}{l}\text { Are the requirements efficient in performing system } \\
\text { functions }\end{array}$ \\
\hline Response & After revision, review and modeling \\
\hline Q5 & $\begin{array}{l}\text { Does Rq elicited possess expandable capability in terms } \\
\text { of data and functions }\end{array}$ \\
\hline Response & $\begin{array}{l}\text { No. It is restricted by the degree of } \\
\text { Metric-Modularity used in the process of elicitation. }\end{array}$ \\
\hline Q6 & Does Rq provide optimum coupling through modularity \\
\hline Response & $\begin{array}{l}\text { No. Design flaws-especially in logic, business diagrams } \\
\text { implementation is lacking cohesiveness leading to lose } \\
\text { coupling. }\end{array}$ \\
\hline Q7 & Are the $\mathrm{Rq}$ simple? \\
\hline Response & No \\
\hline Q8 & $\begin{array}{l}\text { Do requirements elicited provide security necessary to } \\
\text { control access? }\end{array}$ \\
\hline Response & $\begin{array}{l}\text { Yes. It is achieved only up to } 90 \% \text {. Even after Security } \\
\text { test, application is vulnerable to threats due to abstract } \\
\text { security requirements differing from general } \\
\text { requirements. }\end{array}$ \\
\hline Q9 & Are requirements auditable in terms of functions and data \\
\hline Response & Yes Up to $95 \%$. It is evident from auditing results. \\
\hline Q10 & Are $\mathrm{Rq}$ suffers from redundant statements? \\
\hline Response & Yes. It is observable by Back ward traceability. \\
\hline Q11 & Are $\mathrm{Rq}$ independent of computing system environment? \\
\hline Response & Yes. It is known by System testing results. \\
\hline Q12 & $\begin{array}{l}\text { Does } \mathrm{Rq} \text { be implemented with minimum amount of } \\
\text { code? }\end{array}$ \\
\hline Response & $\begin{array}{l}\text { Not all the times because of ambiguity and abstract } \\
\text { statements }\end{array}$ \\
\hline Q13 & Does $\mathrm{Rq}$ possess maintainability? \\
\hline Response & $\begin{array}{l}\text { Yes. The degree of maintainability is known by Metric } \\
\text { used in the company. }\end{array}$ \\
\hline Q14 & Are the requirements portable? \\
\hline Response & $\begin{array}{l}\text { Yes. The degree of Portability is known by Metric and } \\
\text { cross platform testing }\end{array}$ \\
\hline Q15 & $\mathrm{Rq}$ are they in total conformance with industry standards \\
\hline Response & $\begin{array}{l}\text { Yes. Up to } 80 \% \text { Gap between customer need and } \\
\text { requirement }\end{array}$ \\
\hline Q16 & $\begin{array}{l}\text { Are the requirements presentable and identifiable by all } \\
\text { the users in the same way? }\end{array}$ \\
\hline Response & $\begin{array}{l}\text { No. Because of Gap between customer need and } \\
\text { requirement }\end{array}$ \\
\hline Q17 & Are the requirements customizable? \\
\hline Response & $\begin{array}{l}\text { Yes. Metric- scalability is used to measure. Generally up } \\
\text { to } 75 \% \text { is achieved. }\end{array}$ \\
\hline Q18 & Are the requirements reusable \\
\hline
\end{tabular}




\begin{tabular}{|l|l|}
\hline Response & Yes. Generally up to 50\%. But it is project specific \\
\hline Q19 & Are the requirements design independent \\
\hline Response & $\begin{array}{l}\text { Yes. The degree achieved is dependent on Dependability } \\
\text { metric. }\end{array}$ \\
\hline Q20 & Are the requirements unambiguous? \\
\hline Response & $\begin{array}{l}\text { Yes. Up to 70\%. It is largely dependent on customer } \\
\text { interaction and efficiency of BDM and SME }\end{array}$ \\
\hline
\end{tabular}

Rq- Requirements;

TABLE IV: PRIMARY QUALITY REQUIREMENT FACTORS

\begin{tabular}{|l|l|l|l|}
\hline $\begin{array}{l}\text { S1 } \\
\text { No }\end{array}$ & Factor & $\%$ achieved & Remark \\
\hline 1 & Correctness & $65-70 \%$ & $\begin{array}{l}\text { Due to abstract statements of } \\
\text { client. }\end{array}$ \\
\hline Strategies & $\begin{array}{l}\text { Elicitation techniques-brainstorming, } \\
\text { Interviews, checklists, discussions }\end{array}$ \\
\hline 2 & Consistency & $50-60 \%$ & $\begin{array}{l}\text { Mismatch between business } \\
\text { needs and IT needs }\end{array}$ \\
\hline Strategies & Accuracy & Back and from traceability matrix \\
\hline 3 & $75-80 \%$ & Inefficient elicitation \\
\hline Strategies & Visual board, score board, Dash board \\
\hline 4 & Simplicity & $50-60 \%$ & Business analyst interpretation \\
\hline Strategies & Training to Business analyst \\
\hline
\end{tabular}

Interpretation phase: In this phase the responses are processed with respect to the defined metrics and these results are called as measurement results. Goal attainment can be evaluated based on the measurement results. The responses given in the Table III is evaluated against the given metrics. From Table III, it is apparent that there is a need to achieve $100 \%$ potential in the quality factors required for high quality requirements in order to achieve total customer satisfied products as product gets developed based on specified requirements. Unambiguity, correctness, consistency and simplicity are the primary factors, on which the rest of the deciding factors of requirements quality such as security, reliability, and reusability depend upon. Hence, a deeper analysis is done on the above stated primary factors and illustrated in Table IV. The remark column states the rationale for not able to achieve 100 percent strength in that respective area. Strategies indicate the approaches followed in the industry as one of their quality policy to develop customer satisfied products.

Inferences: From the Table IV, it is evident that, correctness, consistency, accuracy and simplicity are the fundamental factors which determine the quality of requirements. The desired degree of attainment of correctness, consistency, accuracy and simplicity quality factors attained in the industry has fallen in the range $65-70 \%$, $50-60 \%, 75-80 \%$ and $50-60 \%$ respectively. Other quality factors such as reliability, security, traceability etc are dependent on fundamental quality factors. From the responses it is evident that industry currently lacks to achieve total strength in basic quality factors of requirements. Since the fundamental factors are not achieved to the fullest extent, the quality attributes of requirements which are dependent on primary factors are as well not achieved to the required extent. Non attaintment of quality attributes in requirements results in project failure. This research work brings out the underplaying reasons for not achieving the total strength in primary quality requirement factors. Efficient strategies are therefore required to be developed in order to achieve the quality of requirements.

\section{CONCLUSION}

Success of the project in terms of project adherence to faster, accurate and customer satisfaction delivery process is very vital for the survival of software industries in the current business world. Requirements lay a strong and fundamental foundation on which projects are built. In order to drive the project towards success, requirements must be embedded with quality hallmark. This research aimed to comprehend the strategies existing in various software industries to emerge out with quality requirements. Since, requirements quality can be judged through quality factors, criteria and metrics, this investigation led to formulate questionnaire. Questionnaire aimed to bring out the current quality status in requirements engineering process and impact of requirements in other stages of SDLC. Response sheet indicates need for quality improvements in terms of correctness, unambiguity and consistency to improve the existing strategies that are conventionally followed in IT industries. Further, there is scope for progressive research in the area of requirements engineering process which leads towards selection of apt strategies in order to realize high quality software requirement specifications.

\section{RFERENCES}

[1] D. Pandey et al., "A Framework for modelling software requirements," IJCSI International Journal of Computer Science Issues, vol. 8, issue 3 , no. 1, May 2011.

[2] D. G. Firesmith, “Are your requirements complete?” Journal of Object Technology, vol. 4, no. 1, January-February 2005, pp. 27-43.

[3] R. A. Majid, "A Survey on user involvement in Software Development Life cycle from practitioners perspectives," presented at 5th International Conference on Computer Science and Convergence Information Technology, Seoul, December 2010.

[4] Weber and J. Weisbrod, "Requirements Engineering in Automotive Development: Experiences and Challenges," in Proc. Requirements Engineering, 2002.

[5] A. M. Davis and D. Zowghi, Good requirements practices are neither necessary nor sufficient, Springer-Verlag London Limited 2004.

[6] T. P. Pushpavathi, V. Ramaswamy, and V. Suma, "Analysis of Quality of Software Projects using Data Clustering Techniques," Amrita International Conference of Women in Computing (AICWIC), 2013, 9th -11 th January, Coimbatore, India.

[7] T. Glib, "Level 6: why we can't get there from here," Software, IEEE, vol. 13, no. 1, pp. 97-98, Jan. 1996.

[8] N. E. Fenton and S. L. Pfleeger, Software Metrics - A Rigorous and Practical Approach, 2nd edition, International Thomson Publishing, 1997.

[9] V. R. Basili and H. D. Rombach, "The tame project: towards improvement-oriented software environments," IEEE Transactions on Software Engineering, vol. 14, no. 6, pp. 758-773, 1988.

[10] L. Chung and N. Subramanian, "Process-oriented metrics for software architecture adaptability", in Proc. the IEEE International Conference on Requirements Engineering, 2001, pp. 310-311.

[11] S. Konrad and M. G. Siemens, "Requirements Engineering in theDevelopment of Large-Scale Systems," presented at $16^{\text {th }}$ IEEE International Requirements Engineering Conference.

[12] N. Nurmuliani, D. Zowghi, and S. Fowell, "Analysis of requirements Volatility during software Development Life cycle," presented at ASWEC'04, Australia, 2004.

[13] T. R. G. Nair and V. Suma, "Pattern of Software Defects Spanning Across Size Complexity," International Journal of Software Engineering, vol. 3, no. 2, July 2010.

[14] T. R. G. Nair and V. Suma, "Implementation of depth of inspection metric and inspection performance metric for quality management in software development life cycle," International Journal of Productivity and Quality Management, InderScience Publishers, USA, 2011. 


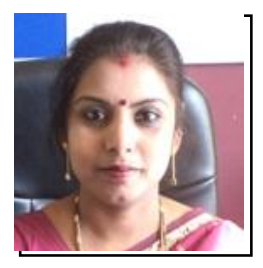

V. Suma has obtained her Ph.D. in Computer Science and Engineering. She is currently, Dean and Head of Advanced Software Engineering Research Groups in Research and Industry Incubation Centre, Dayananda Sagar Institutions, India. She has published several International publications, which include IEEE, ASQ, Crosstalk, IET Software, ACM, IJPQM, etc. Her research results are published in NASA, UNI trier, Microsoft, CERN, IEEE, ACM portals, Springer etc. She is an invited author for International Book Chapter. Her area of interest includes Software Engineering, Cloud Computing, Data Mining, and Information Systems.

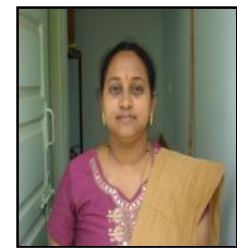

B. R. Shubhamangala is pursuing her Ph.D in software engineering. She is currently a faculty of MCA department, Dayanadasagar Institutions, India. She has published several publications in reputed publications which includes IEEE, Springer, EI compendex 